\title{
Commentary: The next giant leap forward-Long-term outcomes after cardiac surgery
}

\author{
Robert B. Hawkins, MD, MSc, and J. Hunter Mehaffey, MD, MSc
}

\author{
From the Division of Thoracic and Cardiovascular Surgery, University of Virginia, Charlottesville, Va. \\ Disclosures: Authors have nothing to disclose with regard to commercial support. \\ Received for publication Aug 2, 2019; accepted for publication Aug 2, 2019; available ahead of print Oct 6, 2019. \\ Address for reprints: Robert B. Hawkins, MD, MSc, Department of Thoracic and Cardiovascular Surgery, Uni- \\ versity of Virginia, PO Box 800679, Charlottesville, VA, 22908 (E-mail: rbh6x@ virginia.edu). \\ J Thorac Cardiovasc Surg 2020;159:e175 \\ $0022-5223 / \$ 36.00$ \\ Copyright (c) 2019 by The American Association for Thoracic Surgery \\ https://doi.org/10.1016/j.jtcvs.2019.08.026
}

The Society of Thoracic Surgeons Adult Cardiac Surgery Database has been the criterion standard surgical quality and outcomes registry for decades. ${ }^{1}$ It is a researcher's treasure trove of millions of patient records, with hundreds of validated data points collected for each. It has driven quality improvement efforts since its inception in 1989, and the hundreds of thousands of patients who undergo cardiac surgery every year directly benefit. Yet any database is only as good as the variables collected. Although the data forms are routinely updated to keep up with surgical innovation, they are limited to short-term outcomes. The question is whether this accurately reflects true quality, or whether longer-term outcomes are needed to assess more completely the performance of surgeons and hospitals.

In this edition of the Journal, Mori and colleagues ${ }^{2}$ help to point out exactly why additional efforts at high-quality long-term outcomes assessments are needed. They performed a single-center retrospective analysis of all mitral valve operations from 2011 to 2016. Mori and colleagues ${ }^{2}$ use a subjective assessment of mortality trends through 2 years. For patients undergoing mitral valve repair, the risk of death returns to baseline after approximately 90 days, whereas for patients undergoing mitral valve replacement, the risk of death persists out to 180 days. The study has a number of significant limitations, including small sample size, heterogenous operative characteristics, a lack of generalizability, suboptimal follow-up, and subjective analytic technique. Their results are consistent with previous publications. In fact, quantitative methods confirm the finding of Mori and colleagues ${ }^{2}$ that longer-term postoperative risk exists. ${ }^{3}$ In the Netherlands, Siregar and colleagues $^{3}$ found that risk persisted to 120 days for combined coronary and valve cases. All these results suggest that we need to do better as a specialty. Although long-term mortality is a good starting point, patients may be interested in other quality of life metrics as well. Efforts to obtain 1-year patient reported outcomes are difficult, time consuming, and expensive; however, the results are

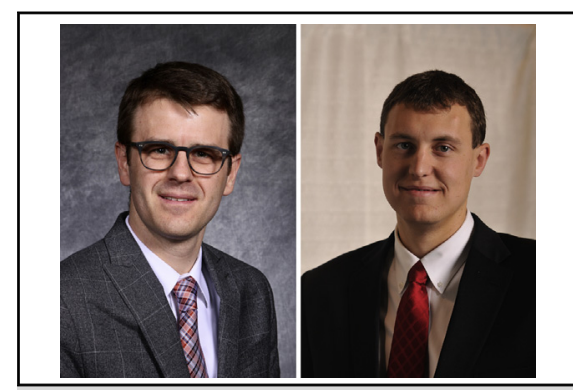

Robert B. Hawkins, MD, MSc (left), and J. Hunter Mehaffey, MD, MSc (right)

\section{Central Message}

Mortality risk remains elevated after mitral valve surgery as long as 90 to 180 days postoperatively. To best assess and improve quality, our databases should capture these longerterm risks.

See Article page e171.

truly meaningful and demonstrate the long-term benefits of cardiac surgery. ${ }^{4}$ As efforts are underway to try and incorporate these data into the Society of Thoracic Surgeons database, ${ }^{5}$ long-term mortality needs to be included as soon as possible. An ideal design would automate this process and automatically update the Society of Thoracic Surgeons database with national mortality data. We hope that the next big step in modernization will prioritize long-term outcomes while reducing the manual burden of data collection.

\section{References}

1. Winkley Shroyer AL, Bakaeen F, Shahian DM, Carr BM, Prager RL, Jacobs JP, et al. The Society of Thoracic Surgeons adult cardiac surgery database: the driving force for improvement in cardiac surgery. Semin Thorac Cardiovasc Surg. 2015; 27:144-51.

2. Mori M, Yousef S, Pichert M, Vinholo TF, Geirsson A. Elevated risk of death persists beyond 30 days after mitral valve surgery. J Thorac Cardiovasc Surg. 2020; 159:e171-3.

3. Siregar S, Groenwold RH, de Mol BA, Speekenbrink RG, Versteegh MI, Brandon Bravo Bruinsma GJ, et al. Evaluation of cardiac surgery mortality rates: 30-day mortality or longer follow-up? Eur J Cardiothorac Surg. 2013;44:875-83.

4. Charles EJ, Mehaffey HJ, Hawkins RB, Burks SG, McMurray TL, Yarboro LT, et al. One year patient-reported outcomes following cardiac surgery. Ann Surg. 2018;227:S51-2.

5. D'Agostino RS, Jacobs JP, Badhwar V, Fernandez FG, Paone G, Wormuth DW et al. The Society of Thoracic Surgeons adult cardiac surgery database: 2019 update on outcomes and quality. Ann Thorac Surg. 2019;107:24-32. 